\title{
Eating disorders in young adults with insulin dependent diabetes mellitus: a controlled study
}

\author{
Christopher G Fairburn, Robert C/Peveler, Beverley Lavies, J I Mann, Richard A Mayou
}

Abstract

Objective-To determine the prevalence of clinical eating disorders and lesser degrees of disturbed eating in young adults with insulin dependent diabetes and a matched sample of non-diabetic female controls.

Design-Cross sectional survey of eating habits and attitudes in diabetic and non-diabetic subjects.

Setting-Outpatient clinic catering for young adults with diabetes; community sample of nondiabetic women drawn from the lists of two general practices.

Subjects -100 patients with insulin dependent diabetes (54 women and 46 men) aged 17-25 and 67 non-diabetic women of the same age.

Main outcome measures-Eating habits and eating disorder psychopathology were assessed by standardised research interview adapted for the assessment of patients with diabetes (eating disorder examination). Glycaemic control was assessed by glycated haemoglobin assay.

Results - In both non-diabetic and diabetic women disturbed eating was common, and in diabetic women the degree of disturbance was related to control of glycaemia. Twenty of the diabetic women $(37 \%)$ had omitted or underused insulin to influence their weight. This behaviour was not restricted to those with a clinical eating disorder. None of the men showed any features of eating disorders, and none had misused insulin to influence their weight.

Conclusions - There was no evidence that clinical eating disorders are more prevalent in young women with diabetes than in non-diabetic women. Nevertheless, disturbed eating is common and is associated with poor control of glycaemia, and the misuse of insulin to influence body weight is also common in young women with diabetes.

\section{Introduction}

Over the past decade there has been considerable interest in whether or not the clinical eating disorders anorexia nervosa and bulimia nervosa are more prevalent in young women with diabetes mellitus than in non-diabetic women. This question is important because clinical evidence suggests that eating disorders in women with diabetes are associated with poor control of glycaemia ${ }^{14}$ and a high rate of serious physical complications. ${ }^{3}$ It is difficult to determine whether eating disorders are more prevalent for two reasons. Firstly, the prevalence of clinical eating disorders in non-diabetic people is uncertain, ${ }^{5}$ and therefore studies must include a matched non-diabetic control group. Secondly, a clinical interview is needed to distinguish features truly characteristic of clinical eating disorders from those resulting from diabetes and its treatment.

The present study addressed both these methodological issues. It had four aims. The first was to compare the severity and prevalence of the features of eating disorders in young women with diabetes with that in a matched group of non-diabetic women. The second aim was to establish the level of these features in young diabetic men, who share with their female counterparts the possible risk factor of having diabetes but who are not otherwise likely to develop eating disorders. ${ }^{6}$ The third aim was to investigate the relation between eating habits and control of glycaemia. The fourth aim was to determine the frequency of underuse or omission of insulin for the purpose of weight control. This behaviour seems to be common in women with diabetes who have an eating disorder, ${ }^{78}$ but its prevalence in the diabetic population in general is not known.

\section{Methods}

SUBJECTS

The index group of patients was obtained from the case register of a clinic that provides treatment for young adults (aged between 17 and 25 years) who have diabetes. ${ }^{9}$ The clinic serves most such patients from the catchment area of the John Radcliffe Hospital in Oxford, and its case register holds records on all patients referred, whether or not they attend. Patients were included in the study if the diagnosis of diabetes had been made at least one year before the start of the project: Patients whose permanent address was not in Oxfordshire were excluded, as were those who were pregnant.

The comparison group of female subjects without diabetes was extracted from a cohort of women recruited for a community study of the prevalence and aetiology of eating disorders. This cohort was selected at random from the case registers of two local general practices, one in a city suburb and the other serving a rural area. The comparison group was group matched with the index subjects by age and father's social class. Subjects with medical conditions known to influence eating habits or weight were excluded.

\section{PROCEDURE}

The initial contact with index subjects was made at a routine clinic visit. The research interviewer described the study and sought subjects' consent to participate. If this was given, arrangements were made to conduct the research assessment, usually in the patient's home. Patients who did not attend the clinic were contacted by letter, telephone, or home visit. The research assessment consisted of a semistructured interview and the completion of a self report questionnaire. It was emphasised that all information was received in confidence and would not be related back to clinic staff.

The control group was contacted by letter. Subjects were asked whether they would participate in a study of women's eating habits and attitudes. Those who did not reply received a second letter. If there was no response they were contacted by telephone or visited at home and the study was explained to them. If they agreed to take part they were subsequently assessed, in most cases at home. The assessment involved the completion of the same measures as the index group.

\section{ASSESSMENT MEASURES}

The principal measure of the clinical features of eating disorders was the eating disorder examination. 
This is a standardised investigator based research interview of established reliability and validity. . $^{(0-1)}$ It assesses the core features of eating disorders and generates operationally defined diagnoses of eating disorders. It is a measure of present state and is mainly concerned with the preceding four weeks ( 28 days). The interview assesses both the frequency of key behaviour, such as overeating and self induced vomiting, and the severity of features such as dietary restraint and concern about shape and weight. Items measuring the latter features are summarised as subscale scores, which range from 0 to 6 . For the subjects with diabetes, the interview was adapted to distinguish behaviour motivated by having diabetes and the demands of treatment from that attributable to an eating disorder. For example, when assessing food avoidance we took careful note of the reasons for the avoidance. The interview included additional questions concerning the underuse or omission of insulin for the purpose of weight control.

Both groups of subjects were weighed, and they were asked to complete the 26 item eating attitudes test, a self report measure of eating habits and attitudes in which each item is scored on a Likert scale with a range of 0 to 3 , and from which a total score is calculated. ${ }^{14}$ This measure was included to allow comparisons to be made with previous studies. An index of the diabetic subjects' control of glycaemia was obtained from the glycated haemoglobin concentration $^{15}$ measured at the clinic visit nearest the assessment interview. This biochemical test yields a measure of prevailing control of glycaemia over the preceding three months.

\section{STATISTICAL ANALYSES}

Proportions of subjects with specific features of eating disorders were compared using $\chi^{2}$ tests. Normally distributed continuous variables were compared using $t$ tests (assuming unequal variance). Non-normal data (eating disorder examination subscale scores for dietary restraint, concern about shape, and concern about weight) were transformed logarithmically and geometric means compared with $t$ tests.

Power calculation showed that if significant disturbance of eating habits affected $10 \%$ of the nondiabetic young adult female population, and if the risk was increased to $25 \%$ among diabetic subjects, then the study had a $50 \%$ chance of detecting such a difference at the $5 \%$ significance level. To have a $90 \%$ chance of detecting even this large difference, a sample size of 150 subjects in each group would be needed. ${ }^{16}$ Clearly, only a multicentre study could achieve a sample of sufficient size to detect a smaller difference. In contrast with the tests of proportion, however, the comparisons of continuous measures improve the statistical power of the study. The study had a $90 \%$ chance of detecting a $50 \%$ increase in subscale scores at the $5 \%$ significance level.

\section{Results}

CHARACTERISTICS OF THE TWO SAMPLES

In all, 114 patients with diabetes were identified from the clinic case register as being suitable for the study, and of these $103(90 \%)$ agreed to participate. (Four female patients declined to take part, and seven patients could not be traced despite repeated letters, telephone calls, and home visits.) One hundred patients ( 54 women, 46 men) were administered the eating disorder examination: one subject was excluded because of profound deafness, one because of significant mental handicap, and another because physical handicap affected her eating. All the patients were receiving treatment with insulin. The mean duration of diabetes was $9 \cdot 2$ years $($ SD $5 \cdot 2)$ for the women and $10 \cdot 1$ years $(5 \cdot 2)$ for the men.
The group of female subjects without diabetes constituted $85 \%$ of those eligible to take part. After matching by age and paternal social class, 67 women were identified for comparison with the female subjects with diabetes. The demographic characteristics of the two samples did not differ significantly (table I).

TABLE I-Characteristics of sample of young adults with diabetes and matched sample of non-diabetic women

\begin{tabular}{|c|c|c|c|}
\hline & \multicolumn{2}{|c|}{ Diabetic patients } & \multirow{2}{*}{$\begin{array}{c}\text { Non-diabetic } \\
\text { women } \\
(n=67)\end{array}$} \\
\hline & $\begin{array}{l}\text { Women } \\
(\mathrm{n}=54)\end{array}$ & $\begin{array}{c}\text { Men } \\
(n=46)\end{array}$ & \\
\hline \multirow{2}{*}{\multicolumn{4}{|c|}{$\begin{array}{l}\text { Percentage (No) from social class: } \\
\text { Pon }\end{array}$}} \\
\hline & & & \\
\hline I & $7(4)$ & $4(2)$ & $5(3)$ \\
\hline II & $21(11)$ & $28(13)$ & $25(17)$ \\
\hline III non-manual & $12(6)$ & $15(7)$ & $8(5)$ \\
\hline III manual & $23(12)$ & $23(11)$ & $24(16)$ \\
\hline IV & $18(10)$ & $15(7)$ & $18(12)$ \\
\hline $\mathrm{V}$ & $9(5)$ & $6(3)$ & $6(4)$ \\
\hline Percentage (No) students & $13(7)$ & $12(5)$ & $12(8)$ \\
\hline Percentage (No) unmarried & $80(43)$ & $84(39)$ & $65(44)$ \\
\hline
\end{tabular}

EATING DISORDERS IN DIABETIC AND NON-DIABETIC WOMEN

Table II shows the prevalence and severity of core eating disorder features in the two samples of women. With one exception, comparison of these two groups showed no significant differences between them in terms of subscale scores on the eating disorder examination or proportions engaging in specific eating behaviours. The exception was the proportion of women with four or more episodes of objective overeating (substantial overeating without loss of control), which was lower in the diabetic group (4/54 $v 15 / 67$; $\left.\chi^{2}=5 \cdot 07, \mathrm{df}=1, \mathrm{p}=0 \cdot 02\right)$. Scores on the self report eating attitudes test were higher in women with diabetes $(12.4 v 8 \cdot 1 ; t=2 \cdot 5, \mathrm{df}=112, \mathrm{p}<0.01)$ than in non-diabetic women. It should be noted that 15 significance tests were performed, and one in 20 tests would be expected to reveal a significant finding by chance.

The eating disorder examination allows operational diagnoses of eating disorders to be made, based on the most widely used scheme. ${ }^{17}$ Three disorders are recognised: anorexia nervosa, bulimia nervosa, and "eating disorder not otherwise specified." None of the women with diabetes met diagnostic criteria for anorexia nervosa; three met criteria for bulimia nervosa; and three met criteria for eating disorder not otherwise specified. The corresponding figures for the comparison sample were nought, two, and three, respectively.

\section{EATING DISORDERS IN DIABETIC MEN AND WOMEN}

Apart from episodes of objective overeating, a feature of no diagnostic significance, the men reported none of the behaviour characteristic of people with eating disorders (table II). The intensity of their self imposed dietary restriction was less than that of the diabetic women $(0.2 v 1.0 ; t=3.8, \mathrm{df}=98, \mathrm{p}<0.001)$, as was their degree of concern about shape $(0.2 v 1.3$; $t=4.8, \mathrm{df}=98, \mathrm{p}<0.001)$ and about weight $(0.3 v 1 \cdot 2$; $t=4 \cdot 1, \mathrm{df}=98, \mathrm{p}<0 \cdot 001)$. Their mean score on the eating attitudes test was also lower than that of the women $(7 \cdot 8 v 12 \cdot 4 ; t=2 \cdot 6 ; \mathrm{df}=98, \mathrm{p}<0 \cdot 01)$. None of the men met diagnostic criteria for any of the three forms of clinical eating disorder.

\section{UNDERUSE OF INSULIN}

Many of diabetic women $(20 / 54,37 \%)$ had underused or even omitted insulin specifically to control their weight, and six (11\%) were currently doing so. Four of these six women had a clinical eating disorder. The frequency of insulin misuse varied greatly and did not seem to be related to whether or not there was a 


\begin{tabular}{|c|c|c|c|c|}
\hline & \multicolumn{2}{|c|}{ Diabetic subjects } & \multirow{2}{*}{$\begin{array}{l}\text { Non-diabetic } \\
\text { women } \\
(n=67)\end{array}$} & \multirow[b]{2}{*}{$\begin{array}{l}\text { Comparison of } \\
\text { women }\end{array}$} \\
\hline & $\begin{array}{c}\text { Men } \\
(n=46)\end{array}$ & $\begin{array}{l}\text { Women } \\
(\mathrm{n}=54)\end{array}$ & & \\
\hline $\begin{array}{l}\text { No (\%) with any objective bulimic episodes (uncontrolled overeating) } \\
\text { No }(\%) \text { with } \geqslant 4 \text { episodes }\end{array}$ & & $\begin{array}{r}10(19) \\
4(7)\end{array}$ & $\begin{array}{l}8(12) \\
3(5)\end{array}$ & $\begin{array}{l}\text { NS } \\
\text { NS }\end{array}$ \\
\hline $\begin{array}{l}\text { No (\%) with any objective overeating (without loss of control) } \\
\text { No }(\%) \text { with } \geqslant 4 \text { episodes }\end{array}$ & $\begin{array}{l}9(20) \\
3(7)\end{array}$ & $\begin{array}{r}15(28) \\
4(7)\end{array}$ & $\begin{array}{l}24(36) \\
15(22)\end{array}$ & $\begin{array}{c}N S \\
p=0 \cdot 02\end{array}$ \\
\hline $\begin{array}{l}\text { No }(\%) \text { with self induced vomiting } \\
\text { No }(\%) \text { abusing laxatives } \\
\text { No }(\%) \text { currently underusing insulin } \\
\text { No }(\%) \text { underusing insulin in the past } \\
\text { No }(\%) \text { currently omitting insulin } \\
\text { No }(\%) \text { omitting insulin in the past }\end{array}$ & & $\begin{array}{rr}1 & (2) \\
4 & (7) \\
4 & (7) \\
12 & (22) \\
2 & (4) \\
4 & (7)\end{array}$ & $\begin{array}{ll}4(6) \\
1(1)\end{array}$ & $\begin{array}{l}\text { NS } \\
\text { NS }\end{array}$ \\
\hline $\begin{array}{l}\text { Dietary restraint (geometric mean of EDE subscale) } \\
\text { Concern about shape (geometric mean of EDE subscale) } \\
\text { Concern about weight (geometric mean of EDE subscale) }\end{array}$ & $\begin{array}{l}0 \cdot 2 \\
0 \cdot 2 \\
0 \cdot 3\end{array}$ & $\begin{array}{l}1 \cdot 0 \\
1 \cdot 3 \\
1 \cdot 2\end{array}$ & $\begin{array}{l}0 \cdot 8 \\
1 \cdot 3 \\
1 \cdot 1\end{array}$ & $\begin{array}{l}\text { NS } \\
\text { NS } \\
\text { NS }\end{array}$ \\
\hline $\begin{array}{l}\text { Mean }(\mathrm{SD}) \text { eating attitudes test score } \\
\text { Mean }(\mathrm{SD}) \text { body mass index }\left(\mathrm{kg} / \mathrm{m}^{2}\right)\end{array}$ & $\begin{array}{r}7 \cdot 8(6 \cdot 7) \\
23 \cdot 0(2 \cdot 6)\end{array}$ & $\begin{array}{l}12 \cdot 4(10 \cdot 4) \\
24 \cdot 6(4 \cdot 6)\end{array}$ & $\begin{array}{r}8 \cdot 1(8 \cdot 1) \\
23 \cdot 5(3 \cdot 2)\end{array}$ & $\begin{array}{l}\mathrm{p}<0 \cdot 01 \\
\mathrm{NS}\end{array}$ \\
\hline
\end{tabular}

$\mathrm{NS}=$ Not significant EDE $=$ eating disorder examination.

$\star$ Identified with version $10 \cdot 3$ of the eating disorder examination; referring to previous 28 days.

concurrent eating disorder. None of the men had ever misused insulin to influence their weight.

\section{QUALITY OF CONTROL OF GLYCAEMIA}

The mean concentration of glycated haemoglobin was higher in the women than the men $(11.5(2.8) v$ $10 \cdot 3(2 \cdot 1) ; t=2 \cdot 4, \mathrm{df}=96, \mathrm{p}=0 \cdot 01)$. Those diabetic women who met diagnostic criteria for bulimia nervosa or eating disorder not otherwise specified or who had frequent episodes of substantial overeating (at least four episodes over the previous 28 days) had higher concentrations of glycated haemoglobin than the remainder of the women $(13 \cdot 3(3 \cdot 0) v 11 \cdot 1(2 \cdot 6) ; t=2 \cdot 2$, $\mathrm{df}=50, \mathrm{p}=0 \cdot 02$ ).

\section{Discussion}

The prevalence of clinical eating disorders in patients with diabetes is important, as disturbed eating is common among young women ${ }^{5}$ and potentially hazardous for those with diabetes. This study, primarily through the use of a matched control group and a specifically adapted standardised interview, has overcome most of the limitations of earlier work. Although a very large sample would be required to conclude with confidence that clinical eating disorders are not more common in women with diabetes than in non-diabetic women,$^{18}$ our use of a validated continuous measure of psychopathology gives no grounds for thinking that this is so.

Our finding contrasts with the conclusion of most existing studies, which has been that eating disorders are more prevalent in young women with diabetes. ${ }^{1341920}$ We believe that there are three reasons for this discrepancy. Firstly, most studies have relied on self report questionnaires, either to measure eating disorder features or to make diagnoses, or both. This is likely to yield a spuriously high estimate of the level of features of eating disorders. Our findings show that, had we also relied on a self report questionnaire such as the eating attitudes test, we too would have concluded that there is more disturbance in young women with diabetes. By using an interview to identify features of eating disorders and to distinguish them from similar behaviour that is the product of treatment we obtained a different finding.

The second reason concerns the choice of diabetic sample. Most studies have focused on patients attending tertiary referral centres, a group in which eating disorders may be overrepresented because of the complicating effect these disorders have on the management of the disorder. ${ }^{82122}$ In contrast, we studied patients registered with a clinic thought to serve most young diabetic patients from a defined geographical area and therefore a group more representative of young people with diabetes.

The third reason for the discrepancy with previous studies relates to estimates of the prevalence of eating disorders in people who do not have diabetes. There are no satisfactory data on the prevalence of clinical eating disorders in the community, yet few of the studies to date have included control groups, and none has adopted our labour intensive, but necessary, strategy of assessing an entire matched non-diabetic control sample with the same standardised measures as were used with those who had diabetes. It is our view that only in this way can valid comparisons be made between the prevalence of eating disorders in those with and without diabetes. It is likely that these three methodological differences account for the finding that the features of clinical eating disorders are as common in non-diabetic people as they are in those with diabetes.

Although the eating habits of young women with diabetes seem to be no more disturbed than those of women in the general population, this level of disturbance is of concern because it is associated with poor control of glycaemia, ${ }^{12423}$ a finding confirmed in this study. The poor control of glycaemia of women with disturbed eating may account for the high rate of serious physical complications in patients with eating disorders and diabetes. ${ }^{3}$ Longitudinal studies are required to examine further the relation between eating habits and control of glycaemia.

An additional finding concerns the misuse of insulin to influence body weight. Insulin misuse is not generally thought to be common, ${ }^{24}$ and omission or underuse of insulin specifically for weight control has received little attention outside clinical reports of patients with eating disorders. Our findings suggest that this practice is widespread in young women and not confined to those who have a clinical eating disorder. It seems not to occur in men.

For the clinician the findings of this study emphasise the importance of considering an eating dtsorder, or at least disturbed eating, as a cause of poor control of glycaemia in young women with diabetes. In our sample $11 \%$ of the women met diagnostic criteria for a clinical eating disorder, many more had highly disturbed eating habits, and $11 \%$ were currently underusing or omitting insulin to influence their weight. In contrast, diabetic men, in common with their non-diabetic counterparts, do not seem to develop clinical eating disorders, and they do not misuse insulin to control their weight. Thus in young men with diabetes poor control of glycaemia may have a different explanation.

Patients with diabetes who have clinical eating 
disorders, as well as those with lesser degrees of disturbed eating, merit specialised help. Treatment approaches that deal with both the behaviour and attitudes characteristic of these patients seem to show promise. ${ }^{25} 26$

We thank the staff and patients of the Young Adult Diabetic Clinic at the John Radcliffe Hospital in Oxford for their help with this study and the general practitioners who gave us access to their case registers. Sarah Beglin helped greatly in generating data on the control sample. The study was supported by a project grant from the Mental Health Foundation (to RAM and CGF) and a programme grant from the Wellcome Trust (to CGF). RCP was supported by a Wellcome Trust Research training fellowship in mental health. CGF is a Wellcome Trust senior lecturer. This paper was prepared while CGF was a fellow at the Center for Advanced Study in the Behavioral Sciences at Stanford Support for this fellowship was provided by the MacArthur Foundation and the Foundations Fund for Research in Psychiatry Endowment.

1 Rodin GM, Daneman D, Johnson LE, Kenshole A, Garfinkel P. Anorexia mellitus: a systematic study. 7 Psychiat Res $1985 \cdot 19 \cdot 381-4$

2 Wing RR, Nowalk MP, Marcus MD, Koeske R, Finegold D. Subclinical eating disorders and glycemic control in adolescents with type I diabetes. Diabetes Care 1986;9:162-7.

3 Steel JM, Young RJ, Lloyd GG, Clarke BF. Clinically apparent eating disorders in young diabetic women: associations with painful neuropathy and other complications. BMF 1987;294:859-62.

4 Steel JM, Young RJ, Lloyd GG, MacIntyre CCA. Abnormal eating attitudes in young insulin-dependent diabetics. Br f P'sychiatry 1989;155:515-21.

Fairburn CG, Beglin SJ. Studies of the epidemiology of bulimia nervosa. A $m$ F Psychiatry 1990;147:401-8.

New York: Guilford Press, 1990.

7 Szmukler GI, Russell GFM. Diabetes mellitus, anorexia nervosa and bulimia. Brf Psychiatry 1983;142:305-8.
8 Szmukler GI. Anorexia nervosa and bulimia in diabetes. 7 Psychosom Re's 984;28:365-9.

9 Mayou RA, Peveler RC, Davies B, Mann JI, Fairburn CG. Psychiatric morbidity in young adults with insulin-dependent diabetes mellitus. Psychol Med (in press)

10 Copper Z, Fairburn $\mathrm{CG}$. The eating disorder examination: a semi-structured interview for the assessment of the specific psychopathology of eating disorders. Int 7 Euting Disorders 1987:6:1-8.

11 Cooper Z, Cooper PJ, Fairburn CG. The validity of the eating disorder examination and its subscales. Br. F Psychiatry 1989;154:807-12.

12 Wilson GT, Smith D. Assessment of bulimia nervosa: an evaluation of the eating disorder examination. Int $\mathcal{F}$ Eating Disorders 1989;8:173-9.

13 Rosen JC, Vara L, Wendt S, Leitenberg H. Validity studies of the eating disorder examination. Int $\mathcal{f}$ Eating Disorders 1990;9:519-28.

14 Garner DM, Olmsted MP, Bohr Y, Garfinkel PE. The eating attitudes test: psychometric features and clinical correlates. Psychol Med 1982;12:871-8.

15 Nathan DM, Singer DE, Hurxthal K, Goodson JD. The clinical information value of the glycosylated haemoglobin assay. $N$ Engl f Med 1984;310:341-6. 16 Fleiss JL. Statistical methods for rates and proportions. New York: Wiley, 1981. 17 American Psychiatric Association. Diagnostic and statistical manual of mental disorders. Third edition, revised (DSM-III-R). Washington, DC: APA, 1987.

18 Robertson P, Rosenvinge JH. Insulin-dependent diabetes mellitus: a risk factor in anorexia nervosa or bulimia nervosa? An empirical study of 116 women. F Psychosom Res 1990;34:535-41.

19 Hudson JI, Wentworth SM, Hudson MS, Pope HG. Prevalence of anorexia nervosa and bulimia among young diabetic women. $\mathcal{F}$ Clin Psychiatry $1985 ; 46: 88-9$.

20 Rosmark B, Berne C, Holmgren S, Lago C, Renholm G, Sohlberg S. Eating disorders in patients with insulin-dependent diabetes mellitus. f Clin Psychiatry 1986;47:547-50.

21 Fairburn CG, Steel JM. Anorexia nervosa in diabetes mellitus. $B M \mathcal{J}$ 1980;280:1167-8.

22 Hillard JR, Hillard PJA. Bulimia, anorexia nervosa and diabetes-deadly combinations. Psychiatr Clin North Am 1984;7:367-79.

$23 \mathrm{La}$ Greca AM, Schwarz LT, Satin W. Eating patterns in young women with IDDM: another look Diabetes Care 1987:10:659-60.

24 Kaminer Y, Robbins DR. Insulin misuse: a review of an overlooked psychiatric problem. Psychosomatics 1989;30:19-24

25 Peveler RC, Fairburn CG. Anorexia nervosa in association with diabetes mellitus: a cognitive-behavioural approach to treatment. Behaviour Research and Therapy 1989:27:95-9.

26 Peveler RC, Fairburn CG. The treatment of bulimia nervosa in patients with diabetes mellitus. Int $f$ Eating Disorders (in press).

(Accepted 25 April 1991)
Department of Surgery,

University of Aberdeen

Eleri L Cusick, FRCSED,

research fellow

Zygmunt H Krukowski,

FRCSED, consultant surgeon

Carol A MacIntosh, FRCSED,

research fellow

Norman A Matheson,

FRCSED, consultant surgeon

Correspondence to:

MrN A Matheson, Ward 49,

Aberdeen Royal Infirmary,

Foresterhill, Aberdeen

AB9 2ZB.

BMF 1991;303:20-2

\section{Risk of neoplasia and malignancy in "dominant" thyroid swellings}

\section{Eleri L Cusick, Zygmunt H Krukowski, Carol A MacIntosh, Norman A Matheson}

\begin{abstract}
Objective-To determine the risk of neoplasia and malignancy in "dominant" thyroid swellings.

Design-Prospective analysis during six years.

Setting-Thyroid clinic serving the Grampian region.

Patients -574 consecutive patients presenting with a discrete thyroid swelling, of whom $179(31 \%)$ were classified clinically as having a dominant area of enlargement within a multinodular gland.

Results-After clinical and cytological assessment 77 dominant swellings were excised. Of the excised swellings, 45 were non-neoplastic and 32 neoplastic, including 11 malignant lesions. The minimum incidence of neoplasia and malignancy in all 179 dominant swellings was therefore $18 \%$ and $6 \%$ respectively.
\end{abstract}

Conclusion-Dominant thyroid swellings should be regarded with greater clinical suspicion than has been traditional.

\section{Introduction}

Although thyroid swellings are common and most are benign, there is a substantial incidence of malignancy in isolated (solitary) swellings, usually quoted at about $20-30 \% .^{1-4}$ Swellings associated with clinically palpable generalised abnormality of the thyroid are generally regarded with much less suspicion. In 1983 Beierwaltes stated, "If palpation reveals palpable enlargement of the ipsilateral lobe containing the nodule and of the opposite lobe also, the probability of the lesion being malignant decreases from $35-45 \%$ range to less than $1 \%$."
To distinguish swellings associated with (and presumably, in pathological terms, most likely part of a generalised thyroid abnormality from clinically isolated swellings we have termed them dominant thyroid swellings. Previously the term dominant has apparently been used neither precisely nor consistently, and some authors use it interchangeably with solitary nodule $^{6}$ or do not distinguish between isolated and dominant swellings in analysing data. ${ }^{\text {? }}$

\section{Patients and methods}

During six years (September 1981 to August 1987) all patients referred with a thyroid swelling to the surgical team at a joint medical and surgical thyroid clinic were entered into a prospective study. On the basis of clinical examination swellings were classified as isolated, dominant, or generalised. A discrete swelling was termed isolated if the thyroid was otherwise impalpable and dominant if there was evidence of a generalised abnormality, usually in the form of a palpable nodularity or enlargement of the contralateral lobe.

Fine needle aspiration cytology and histology-Fine needle aspiration cytology was performed routinely in the outpatient clinic as described ${ }^{8}$ : that paper also gave details of cytological and histological interpretation and data handling.

Terminology and indications for operation - The term neoplastic embraces all follicular neoplasms as well as malignant lesions. According to histological criteria most follicular neoplasms are apparently benign, but careful histological study is the only means of detecting invasive features on which the differentiation between 